\title{
Congenital nephrogenic diabetes insipidus in the Corpus Hippocraticum: The first description
}

\author{
Gregory Tsoucalas, Marianna Karamanou
}

French Institute of the History of Medicine, University "Claude Bernard Lyon 1", Faculty of Medicine, Lyon, France

\section{Dear Editor,}

In congenital nephrogenic diabetes insipidus (cNDI), polyuria and polydipsia are present from birth, as the kidney is unable to concentrate urine despite elevated concentrations of the antidiuretic hormone arginine-vasopressin. ${ }^{1}$ In ancient Greek medicine, physiology was, needless, to say, an as yet fairly undeveloped specialty among medico-philosophers, based as they were mainly on the Hippocratic medical theory of the four humours (blood, phlegm, yellow bile, and black bile) and the "pneuma" (Greek: $\pi v \varepsilon v$ $\mu \alpha$, pneuma $\approx$ air $\approx$ spirit $\approx$ the vital force of life) ${ }^{2}$ Thus, such a complex context as that of cNDI was still terra incognita.

It is widely accepted that the name most linked with diabetes in Greek antiquity was that of Aretaeus of Cappadocia (c. $1^{\text {st }}$ century BC $-4^{\text {rd }}$ century AD). ${ }^{3}$ Aretaeus, employing the Ionian dialect to compose his manuscripts, wrote in such a way that no medical author of antiquity surpasses him in his vivid portrayal of various diseases. Ionian was, in fact, the dialect that had been used by Hippocrates (c. 460-370 BC)

Key words: Ancient Greec, Congenital nephrogenic diabetes insipiduse, Hippocrates, Uroscopy

Address for correspondence:

Gregory Tsoucalas, 155 Ieroloxiton Street Agioi Anargyroi, Volos, P.C. 38334, Greece; E-mail: gregorytsoucalas@yahoo.gr

Received: 16-03-2017, Accepted: 30-03-2017
(Figure 1 and 2) and his followers for the composition of the medical encyclopaedia, the Corpus Hippocraticum. Although Aretaeus' efforts to resemble Hippocrates (inter alia, in his adoption of the Ionic dialect and his similar syntax) indicated, during that era, a measure of vanity, he succeeded in becoming a prestigious therapist, a prolific writer, and an important medical figure for many centuries to come, scientifically distancing himself quite considerably from the "Father of Medicine". ${ }^{4}$

Although Aretaeus largely followed the method of Hippocrates, he showed more devotion to anatomy and physiology than most ancient physicians, a fact that led him to form a sophisticated synthesis of the previous knowledge on various diseases, copiously supplemented by his own observations. Gifted with a unique capacity for observing pathologic phenomena, he gave an accurate description of diabetes, among other diseases, which is considered to be its first delineation in classical antiquity. Meanwhile, it was Apollonius of Memphis who is said to have termed the disease "diabetes", from the Greek verb " $\delta$ l $\alpha \beta \alpha i v \omega$ ", which means "to go or run through". 3,5 As is true of every science, each achievement forms a link in a long "chain" in which numerous inspired persons work on an idea, every one of which advances scientific progress. This fact was well known to Aretaeus who, as mentioned above, furthered the science of medicine through pursuing a more 'pragmatic' course of study and diagnosis than his "mentor", Hippocrates. For, inside the Corpus Hippocraticum a small fragment possibly attests the first observation of what we call today cNDI. ${ }^{2}$ 


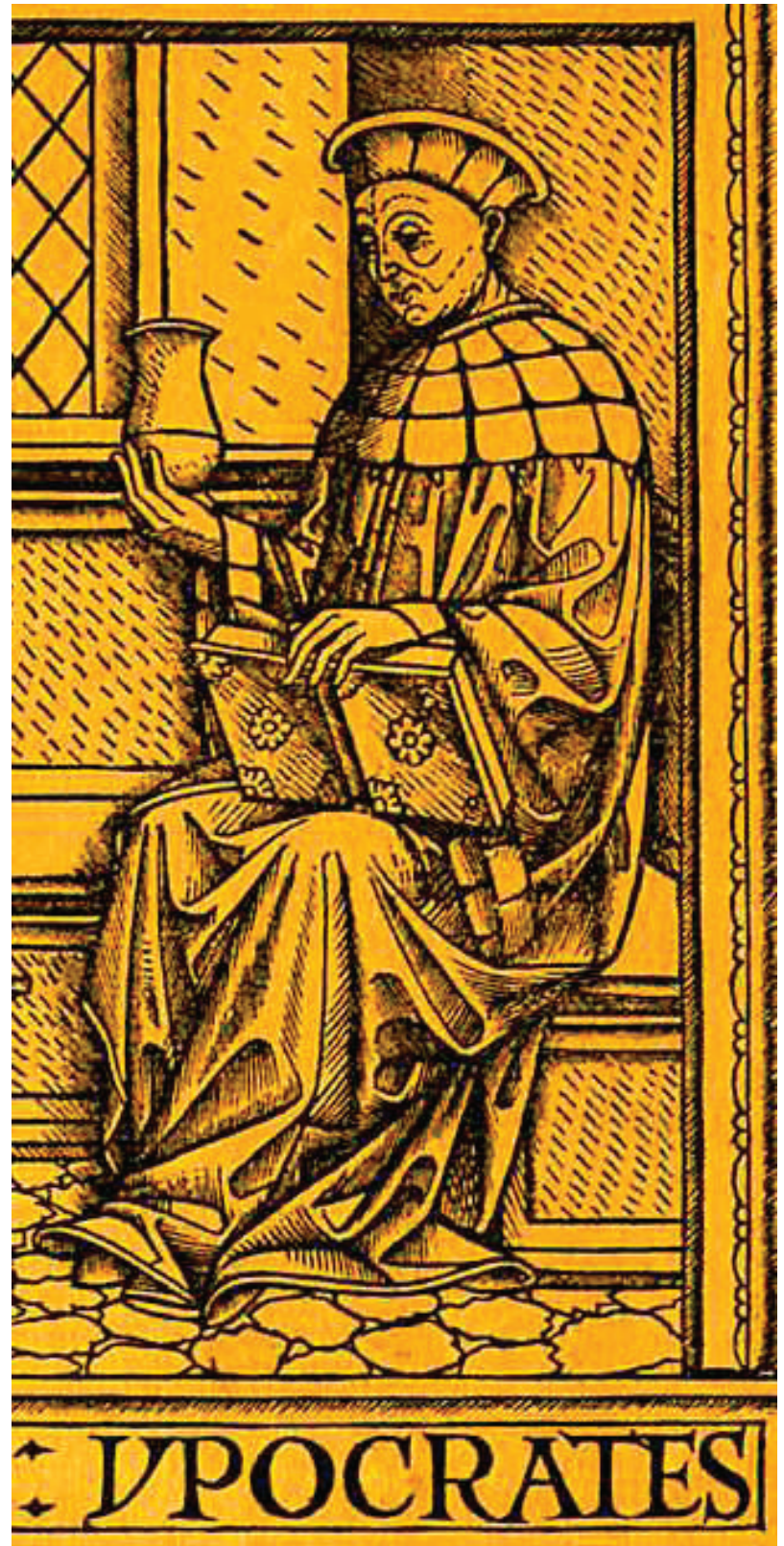

Figure 1. Hippocrates and uroscopy: part of a woodcut from an early 15 th century, Latin language medical book.

It is striking to read today this very perceptive description by Hippocrates: “...the fluids are sucked from the veins to the kidneys, then the watery substance appears to be distilled by the kidneys, where the urine is filtered and separated by the blood" (Greek fragment:

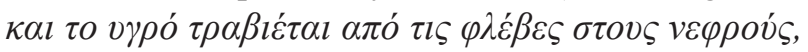

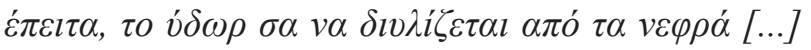

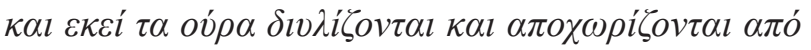

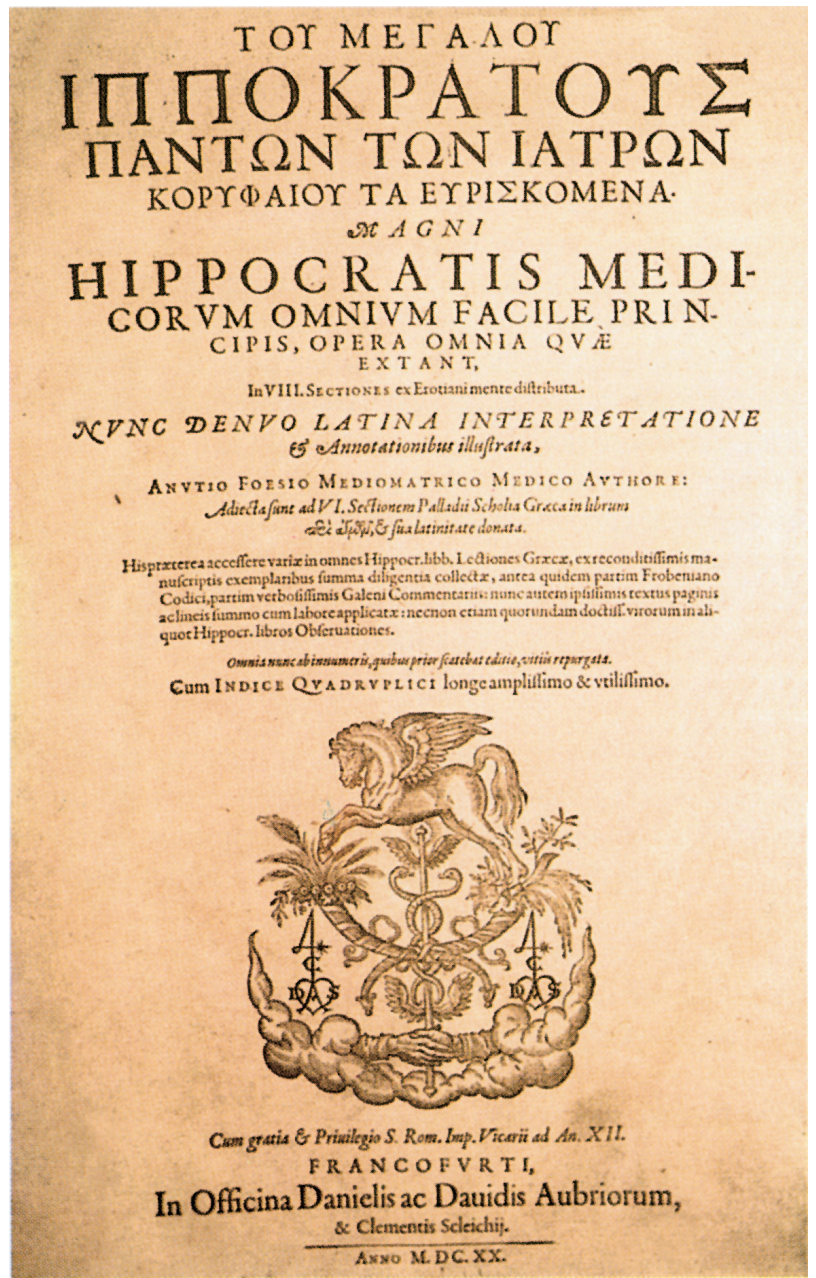

Figure 2. International Hippocratic Foundation of Kos (Frankfurt edition, 1620).

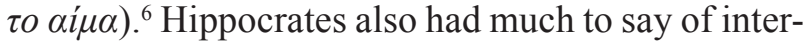
est with regard to childhood diabetes. In his opinion, paediatric kidney diseases presented high mortality and were harder to treat. For Hippocrates, an infant's body was hotter, thus are accompanied by during illness abnormally frequent urination which should be examined via uroscopy. ${ }^{2}$ The most dangerous type of urine for infants was the more watery type by which he seemingly meant the "thinner" or "low specific gravity" type (Greek fragment: $\Theta \alpha v \alpha \tau \omega \delta \varepsilon \delta \sigma \tau \varepsilon \rho \alpha \delta \varepsilon \tau \omega \nu$

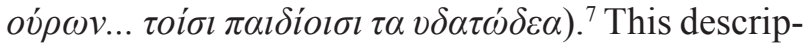
tion of a paediatric nosological entity characterized by polyuria and thinner watery urine, and most probably constituting the first reference to cNDI, seems to have been made by the "Father of Medicine", the brilliant Hippocrates. 


\section{CONFLICT OF INTEREST}

No conflict of interest.

\section{REFERENCES}

1. Bockenhauer D, Bichet DG, 2017 Nephrogenic diabetes insipidus. Curr Opin Pediatr 29: 199-205.

2. Tsoukalas J, 2004 Paediatrics from Homer until today. Thessaloniki-Skopelos: Science Press.

3. Laios K, Karamanou M, Saridaki Z, Androutsos G, 2012 Aretaeus of Cappadocia and the first description of diabetes. Hormones (Athens) 11: 109-113.

4. Tsoucalas G, Sgantzos M, 2016 Aretaeus of Cappadocia (ca 1st-3rd century AD): views on hepatic cancer. J BUON 21: 1326-1331.

5. Adams F, 1856 The extant works of Aretaeus the Cappadocian. London: The Sydenham Society.

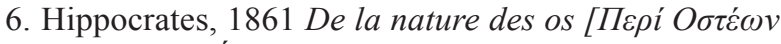

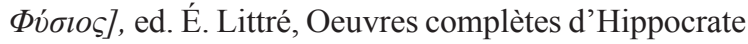
vols 9. Paris: Baillière.

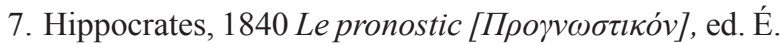
Littré, Oeuvres complètes d' Hippocrate vols 2. Paris: Baillière. 